\title{
A bimetallic nanocomposite electrode for direct and rapid biosensing of p53 DNA plasmid
}

\author{
EZAT HAMIDI-ASL ${ }^{\mathrm{a}}$, JAHAN-BAKHSH RAOOF ${ }^{\mathrm{a}, *}$, NAHID NAGHIZADEH $^{\mathrm{a}}$, \\ SIMIN SHARIFI ${ }^{\mathrm{b}}$ and MOHAMMAD SAEID HEJAZI ${ }^{\mathrm{b}, \mathrm{c}}$ \\ ${ }^{a}$ Eletroanalytical Chemistry Research Laboratory, Department of Analytical Chemistry, Faculty of Chemistry, \\ University of Mazandaran, Babolsar, Iran \\ ${ }^{b}$ Faculty of Pharmacy, Tabriz University of Medical Sciences, Tabriz, Iran \\ ${ }^{c}$ Drug Applied Research Center and Pharmaceutical Nanotechnology Research Center, \\ Tabriz University of Medical Sciences, Tabriz, Iran \\ e-mail: j.raoof@umz.ac.ir
}

MS received 16 February 2015; revised 19 June 2015; accepted 21 June 2015

\begin{abstract}
A new label-free electrochemical DNA biosensor is presented based on carbon paste electrode (CPE) modified with gold $(\mathrm{Au})$ and platinum $(\mathrm{Pt})$ nanoparticles to prepare the bimetallic nanocomposite electrode. The proposed sensor was made by immobilization of 15 -mer single stranded oligonucleotide probe related to p53 gene for detection of DNA plasmid samples. The hybridization detection relied on the alternation in the guanine oxidation signal following hybridization of the probe with complementary genomic DNA. The technique of differential pulse voltammetry (DPV) was used for monitoring guanine oxidation. To optimize the performance of the modified CPE, different electrodes were prepared in various percentages of Au and $\mathrm{Pt}$ nanoparticles. The modified electrode containing 15\% Au/Pt bimetallic nanoparticles (15\% Au/Pt-MCPE) was selected as the best working electrode. The selectivity of the sensor was investigated using plasmid samples containing non-complementary oligonucleotides. The detection limit of the biosensor was studied and calculated to be $53.10 \mathrm{pg} \mu \mathrm{L}^{-1}$.
\end{abstract}

Keywords. Bimetallic nanoparticles; Nanocomposite; DNA plasmid; Biosensor.

\section{Introduction}

Detection, identification and quantification of biomarkers such as proteins and nucleic acids at early disease states are necessary for public health protection. ${ }^{1-3}$ The nucleic acid biosensors have been used for partial gene detection because of their unique advantages such as low-cost, simplicity, miniaturization, etc. ${ }^{4-6}$ DNA hybridization biosensors, also known as genosensors, are analytical devices for the detection of specific DNA target sequences in solution upon hybridization of the targets with complementary probes immobilized on a solid substrate. ${ }^{7}$

Nowadays, the technological platforms that provide biosensors of high sensitivity, selectivity and stability are therefore in high demand. ${ }^{8-10} \mathrm{~A}$ sensor consists of two functional components: a recognition element for binding with target analytes and a transduction process to signal the binding event. The efficiency of these two components is critically related to the outcome of the

*For correspondence detection process. ${ }^{11}$ Nanoparticles possess several distinctive physical and chemical attributes that make them promising synthetic scaffold to improve the detection systems in the sensors. ${ }^{12,13}$ Recently, bimetallic nanocomposite-modified electrodes are used in biosensors, since the addition of the second metal brings about variation in particle size, shape, surface morphology, chemical and physical properties including catalytic activity and chemical selectivity. ${ }^{14-16}$ Among the different nanoparticles, specifically Pt and Au-based bimetallic systems remarkably improved the electroanalytical performance of the sensors. ${ }^{17-19}$

Recently our research group has published several articles in the field of DNA biosensors by introducing novel indicators that can be used for recognition and quantification of nucleic acids such as Indigo Carmine, ${ }^{20}$ Ketamine, ${ }^{21}$ Ethyl Green, ${ }^{22}$ Brilliant Cresyl Blue, ${ }^{23}$ Tyrosinaz, ${ }^{24}$ and Celestine Blue. ${ }^{25}$ In another type of research by our group, well-known indicator such as Methylene Blue was used for investigating a new strategy and optimized the procedure for an electrochemical PNA biosensor, ${ }^{26}$, Zeolite modified carbon paste DNA biosensor ${ }^{27}$ and triplex structure formation. ${ }^{28}$ 
In this work, we extend our research to label-free detection of genosensor to introduce a fast biosensing procedure. We have reported earlier use of magnetic nanoparticles ${ }^{29}$ gold nano-cube modified screen printed electrodes,${ }^{30}$ nanogold-modified carbon paste electrode $(\mathrm{CPE})^{31}$ and multi-wall carbon nanotubes incorporated into CPE. ${ }^{32}$ Here, for the first time, we are reporting the bimetallic nanocomposite biosensor prepared by modification of CPE with gold plus platinum nanoparticles. To the best of our knowledge, there has been no report for the incorporation of binary nanoparticles into the carbon paste and its usage for direct detection of DNA plasmid real samples of p53 gene.

The electrochemical responses of the modified electrodes were investigated by cyclic voltammetry (CV) and electrochemical impedance spectroscopy (EIS). To investigate the hybridization event, the guanine oxidation signal was monitored by differential pulse voltammetry (DPV). The complementary and non-complementary plasmid samples were used in order to test the specificity of the genosensor. The results showed that the label-free biosensor exhibited good reproducibility, long-term stability, high sensitivity and selectivity.

\section{Experimental}

\subsection{Reagents and materials}

A 15-mer oligonucleotide corresponding to short sequence of p53, C1-DNA, was used as the probe and its complementary, G1-DNA, was used as the target DNA. The plasmid with complementary sequence was used as the target DNA in real sample experiments. Also, two other plasmid samples, Pet and TL, with non-complementary oligonucleotides were used in the control experiments. The plasmid samples $\left(37 \mathrm{ng} \mu \mathrm{L}^{-1}\right)$ were prepared as reported elsewhere. ${ }^{33}$ The oligonucleotides were supplied (as lyophilized powder) by MWG-Biotech company, Germany with the following sequences:

Probe DNA, C1, : 5'-AGT TCT CCA TCC CCA-3'

Complementary DNA, G1, : 5'-TGG GGA TGG AGA ACT-3'

The stock solutions of the oligonucleotide $(100 \mu \mathrm{M})$ were prepared with TE buffer solution $(10.0 \mathrm{mM}$ Tris$\mathrm{HCl}, 1.0 \mathrm{mM}$ EDTA, $\mathrm{pH}$ 8.0) and kept frozen. More dilute solutions of the oligonucleotides were prepared using $0.50 \mathrm{M}$ acetate buffer solution $(\mathrm{pH} 4.8)$ containing $20.0 \mathrm{mM} \mathrm{NaCl}$. $\mathrm{HAuCl}_{4}$ and $\mathrm{H}_{2} \mathrm{PtCl}_{6}$ were purchased from Merck Company. Other chemicals were analytical reagent grade and purchased from Fluka. Distilled, deionized and sterilized water was used in all solution preparation. Each measurement consisted of immobilization of probe and detection of target DNA (immobilization/detection cycle) carried out on a fresh working electrode surface. All the experiments were carried out at room temperature in an electrochemical cell.

\subsection{Apparatus}

All the electrochemical experiments were performed using AUTOLAB PGSTAT 30 electrochemical analysis system and GPES 4.9 software package (Eco Chemie, Netherlands). The three electrode system was composed of a CPE or MCPE (surface area of $0.015 \mathrm{~cm}^{2}$ ) as the working electrode, a saturated calomel electrode (SCE) as the reference electrode and a platinum wire as the auxiliary electrode.

To characterize the synthesized nanoparticles, the technique of atomic force microscopy (AFM), Agilent 5100, was used. The AFM images were taken in the tapping mode in ambient condition by using a tip made of Si with Al coating on the back for reflection. The AFM images were analyzed using Gwyddion software (Gwyddion 2.29) to determine the grain size.

\subsection{Procedure}

All parameters in the procedure were optimized before and published elsewhere; ${ }^{23}$ however, briefly, scheme 1 shows the procedure. As seen, the first step is the preparation of the working electrode.

\subsection{Preparation of CPE}

To prepare the carbon paste electrode, graphite powder was mixed with paraffin oil in a ratio of 70:30\% (w/w) by a mortar and pestle. A portion of the resulting paste was packed into the bottom of a glass tube. The electrical connection was implemented via a copper wire fitted into the glass tube. The surface of the electrode was smoothened on a weighing paper and rinsed carefully with distilled water.

\subsection{Preparation of $M C P E$}

Gold nanoparticles were prepared by chemical reduction method as reported in literature. ${ }^{22,31}$ A solution of $0.01 \% \mathrm{HAuCl}_{4}$ was stirred and heated to $100^{\circ} \mathrm{C}$. Then, $1 \%$ sodium citrate was added to the solution until the color change was observed. Subsequently, the solution was left at room temperature in order to cool down gradually. The nanoparticle solution was kept at $4{ }^{\circ} \mathrm{C}$ away from light. To prepare gold nanoparticles-modified carbon paste electrode, the gold nanoparticles solution was 

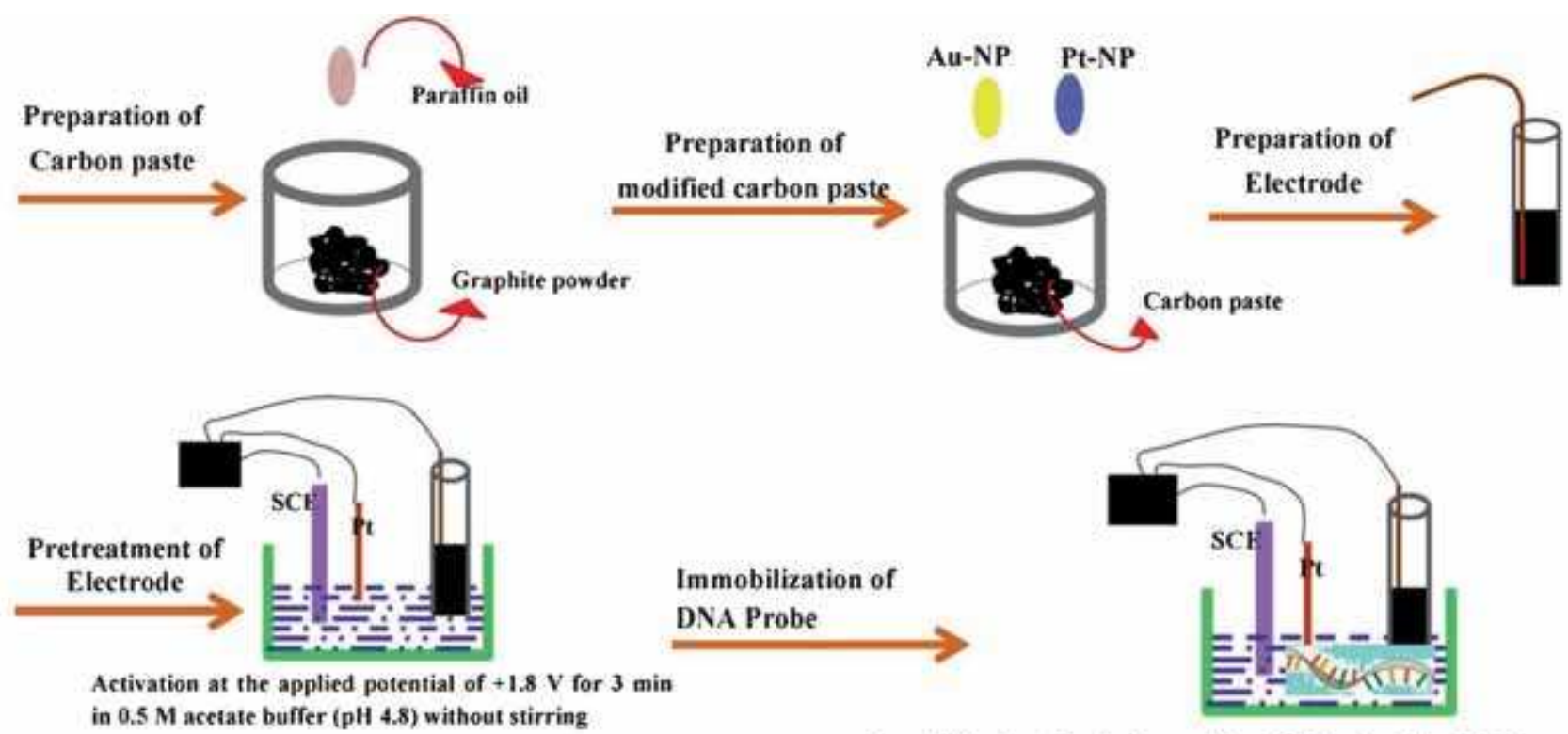

Immobilization of probe by applying $0.50 \mathrm{~V}, 5 \mathrm{~min}$ in $0.50 \mathrm{M}$ acetate buffer solution containing DNA and $20 \mathrm{mM}$ of $\mathrm{NaCl}$ with stirring.

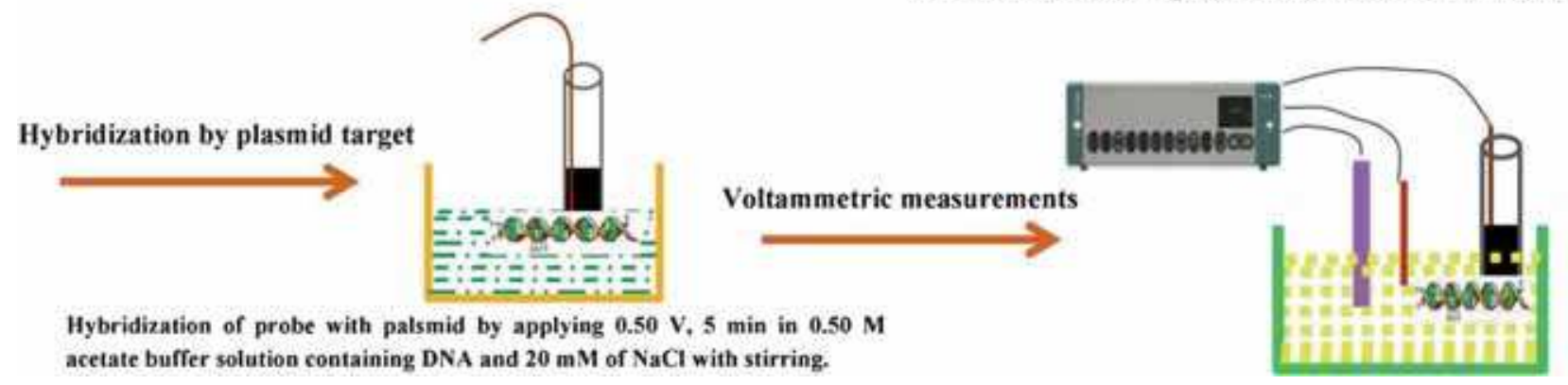

Scheme 1. Procedure for preparing working electrode.

poured over a petri dish in oven to dry. Then, sufficient amount of Au nanoparticles was added to the carbon paste resulted from the previous part to obtain a modified CPE containing desirable percentage of Au nanoparticle (Au-MCPE). The final step, like packing in a tube and smoothing via a weighing paper was similar to the preparation of CPE.

The platinum nanoparticle solution was prepared by mixing $60 \mathrm{~mL}$ of $2 \mathrm{mM}$ aqueous $\mathrm{H}_{2} \mathrm{PtCl}_{6}$ solution with $3 \mathrm{~mL}$ of $50 \mathrm{mM}$ aqueous sodium citrate solution. Then, $7 \mathrm{~mL}$ of $120 \mathrm{mM}$ aqueous $\mathrm{NaBH}_{4}$ solution was added drop wise under vigorous stirring. ${ }^{34}$ The solution was kept stirring for another half an hour. The colloidal solution was covered with aluminum foil and kept as a stock solution. The procedure for preparation of PtMCPE and Au/Pt-MCPE was just similar to preparation of Au-MCPE.

It should be mentioned here that there is no interaction between $\mathrm{Au}$ and $\mathrm{Pt}$ nanoparticles inside the carbon paste. They are two separate particles that have synergic effect on the efficiency of biosensor via formation of binary nanocomposite.

\subsection{Electrochemical activation of the working electrode}

The electrochemical pretreatment of the surface of electrode was performed on the optimized potential of $1.80 \mathrm{~V}$ vs. SCE for $5 \mathrm{~min}$ in $0.50 \mathrm{M}$ acetate buffer solution ( $\mathrm{pH} 4.80$ ) containing $20 \mathrm{mM} \mathrm{NaCl}$ without stirring. The applied potential and time were optimized in previous report, ${ }^{32}$ the imposed potential ranging between -2.0 and $2.5 \mathrm{~V}$. Activity of the electrode was improved when potential exceeded $1.0 \mathrm{~V}$ until reaching to its maximum value at $1.80 \mathrm{~V}$ and then decreased at more positive potentials. When potential was higher than $2.0 \mathrm{~V}$ or lower than $-1.5 \mathrm{~V}$, the oxidation or reduction of supporting electrolyte ions or solvent itself occurred. In voltages higher than $2.0 \mathrm{~V}$, gaseous products were observed significantly at the surface of working electrode that could damage the surface of the working electrode. In the optimized potential of $1.80 \mathrm{~V}$, maximum amount of carbon at the surface of CPE could be oxidized and acquire positive charge. Therefore, they could adsorb higher amount of negatively charged DNA. 


\subsection{Immobilization of the probe on the working electrode}

After activation, for immobilization the probe on the electrode, it was immersed in $0.50 \mathrm{M}$ acetate buffer solution ( $\mathrm{pH} 4.8$ ) containing $1.0 \mu \mathrm{M}$ probe and $20 \mathrm{mM}$ $\mathrm{NaCl}$. Then, the potential of $0.5 \mathrm{~V}$ vs. SCE was applied to the electrode for $5 \mathrm{~min}$ stirring $(200 \mathrm{rpm})$ the solution at room temperature. Then, the electrode was rinsed with sterilized and deionized water. As mentioned in section of 2.6, the influence of imposed potential was investigated and optimized elsewhere. ${ }^{32}$ The imposed potentials were between -0.80 and $0.8 \mathrm{~V}$. It was not possible to apply the potential less than -0.8 or higher than $+0.8 \mathrm{~V}$ for immobilization the probe because of a risk to reduce or oxidize the oligonucleotides of probe.

\subsection{Hybridization}

The hybridization step was done by dipping the probemodified electrode into a stirring hybridization solution
(0.5 M acetate buffer $\mathrm{pH} 4.8)$ containing DNA target and $20 \mathrm{mM} \mathrm{NaCl}$ for $5 \mathrm{~min}$, while the electrode potential was kept at $0.50 \mathrm{~V}$ vs. SCE. The electrode was rinsed with sterilized and deionized water to remove the non-hybridized DNA. Plasmid sample should be pretreated before using in the hybridization step. Therefore, the diluted plasmid was denatured by heating in a water bath at $95^{\circ} \mathrm{C}$ for $5 \mathrm{~min}$ and immersed in an ice bath for $2 \mathrm{~min}$. Thereafter, it can be used as a target.

\subsection{Voltammetric measurements}

The electrochemical investigation of hybridization event was carried out using DPV in $20 \mathrm{mM}$ Tris- $\mathrm{HCl}$ buffer (pH 7.0) solution and the electrode potential was scanned between 0.70 and $1.10 \mathrm{~V}$ vs. SCE at pulse amplitude of $50 \mathrm{mV}$. The raw data were treated using the Savitzky and Golay filter (level 2) of GPES software, followed by the GPES software moving average baseline correction using a peak width of 0.01 . Repetitive measurements
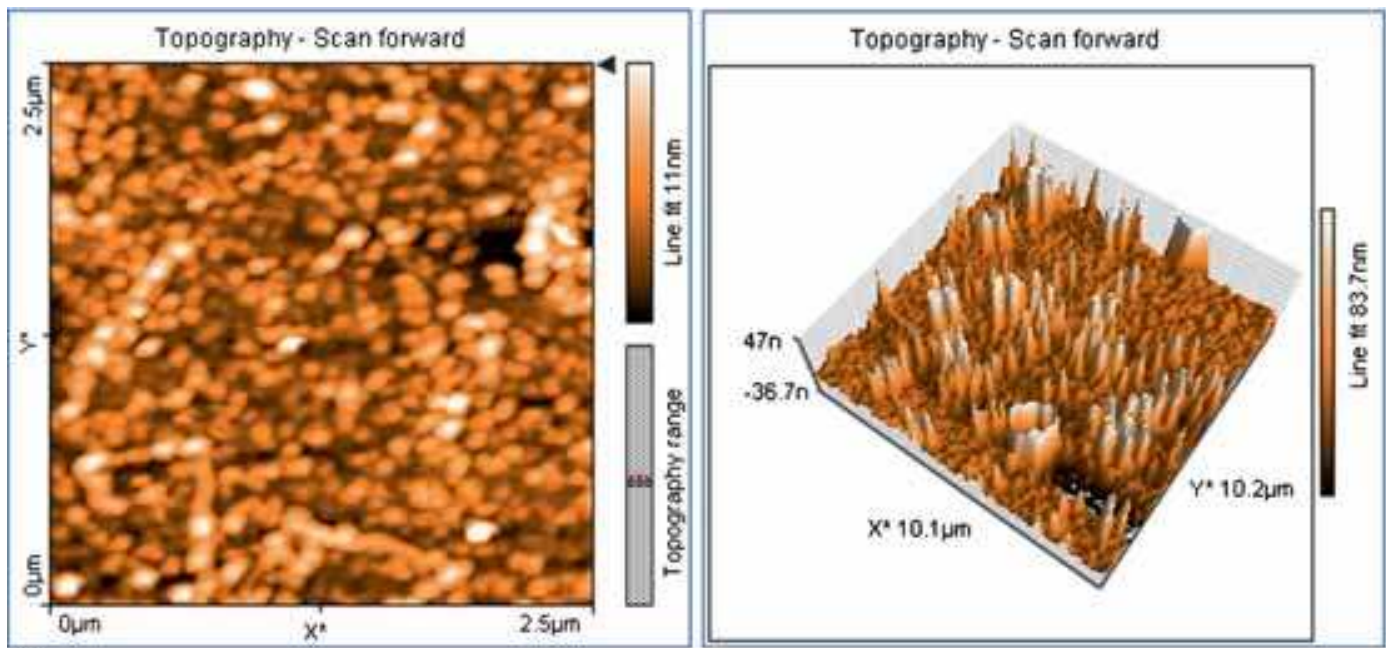

(a)

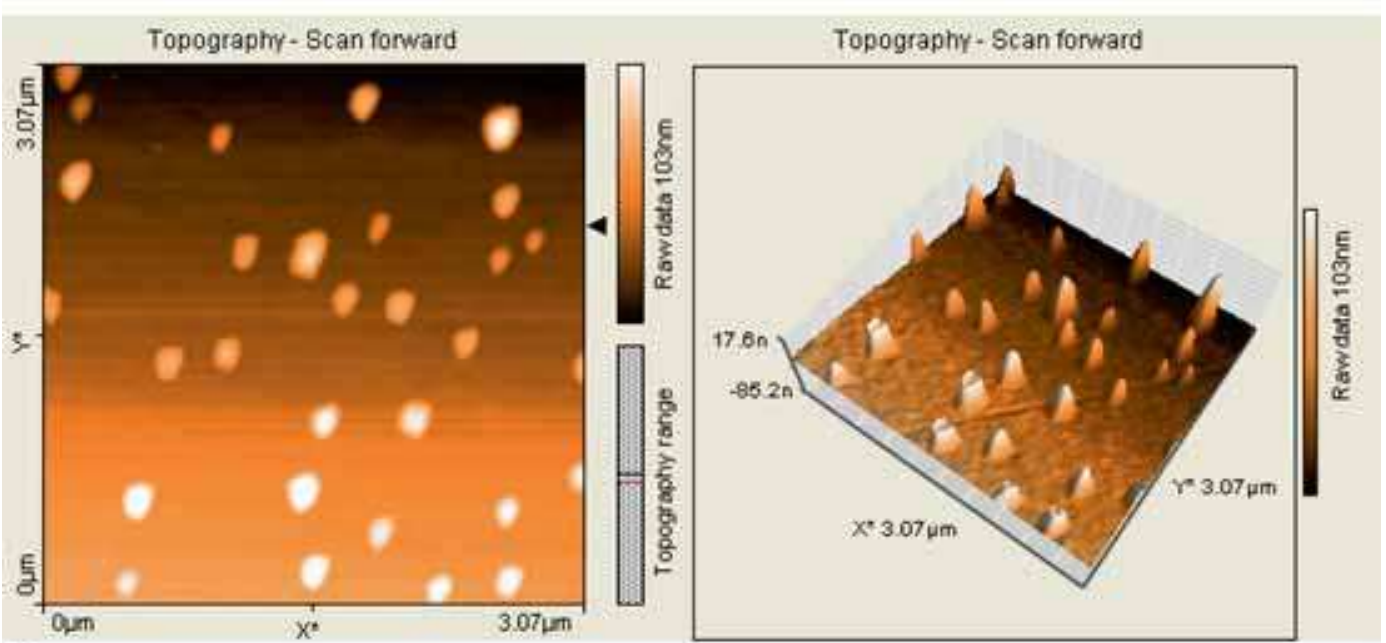

(b)

Figure 1. AFM images of gold (a) and platinum (b) nanoparticles. 
were carried out after renewing the electrode by cutting and polishing the electrode surface.

\subsection{Impedance measurement}

Impedance measurements were carried out in phosphate buffer solution ( $\mathrm{pH} 7.0$ ) containing $1.0 \mathrm{mM} \mathrm{K}_{4} \mathrm{Fe}(\mathrm{CN})_{6}$ $/ \mathrm{K}_{3} \mathrm{Fe}(\mathrm{CN})_{6}$ and $0.1 \mathrm{M} \mathrm{KCl}$ at a bias potential of $0.21 \mathrm{~V}$ vs. SCE. The data are displayed in the complex plane Nyquist plots ( $\mathrm{Z}^{\prime \prime}$ vs. $\mathrm{Z}^{\prime}, \mathrm{Z}^{\prime}$ and $\mathrm{Z}^{\prime \prime}$ being real and imaginary impedances).

\section{Results and Discussion}

\subsection{Preliminary investigation}

Figure 1 shows the AFM images of Au nanoparticles (a) and Pt nanoparticles (b). The average size of Au and Pt nanoparticles are 47.0 and $17.6 \mathrm{~nm}$, respectively.

To investigate the role of nanoparticles in the composition of electrodes, carbon paste electrodes were prepared with different percentage compositions of nanoparticles. Figure 2A shows cyclic voltammograms of electrodes in $0.1 \mathrm{M} \mathrm{KCl}$ solution ( $\mathrm{pH} 7.0$ ) containing $\mathrm{K}_{3} \mathrm{Fe}(\mathrm{CN})_{6} / \mathrm{K}_{4} \mathrm{Fe}(\mathrm{CN})_{6}$ as redox couple (1:1) at a scan rate of $100 \mathrm{mV} \mathrm{s}^{-1}$. The results illustrate the redox signal of $\left[\mathrm{Fe}(\mathrm{CN})_{6}\right]^{3-/ 4-}$ increases significantly after the modification of CPE by $15 \%$ of gold nanoparticles (15\% Au-MCPE, curve b), $15 \%$ of platinum nanoparticles (15\% Pt-MCPE, curve c) and 15\% of gold /platinum nanoparticles (15\% Au/Pt-MCPE, curve d). As seen, the last one shows the highest peak current in cyclic voltammetry. In fact, this result implies that not only the treatment of CPE with nanoparticles has a favorable effect on the electrode response but also gold and platinum nanoparticles have the synergistic effect on each other. ${ }^{35}$

As the electrochemical impedance spectroscopy (EIS) is the most sensitive technique to study the modification of electrode surface among electrochemical methods, it is used to investigate the surface properties. Each of the spectra is composed of a semicircle part in a high frequency region and a linear part in a low frequency region, corresponding to the electron transfer process and the diffusion process, respectively. The diameter of the semicircle represents the charge transfer resistance at the electrode surface $\left(\mathrm{R}_{\mathrm{ct}}\right)$. The linear part in impedance spectra represents the Warburg impedance $\left(\mathrm{Z}_{\mathrm{W}}\right){ }^{26}$ Figure 2B shows the electrochemical impedance spectra at bare CPE (a) and electrodes modified with $15 \%$ of Au nanoparticles (b), Pt nanoparticles (c) and $\mathrm{Au} / \mathrm{Pt}$ bimetallic nanoparticles (d). The high frequency section
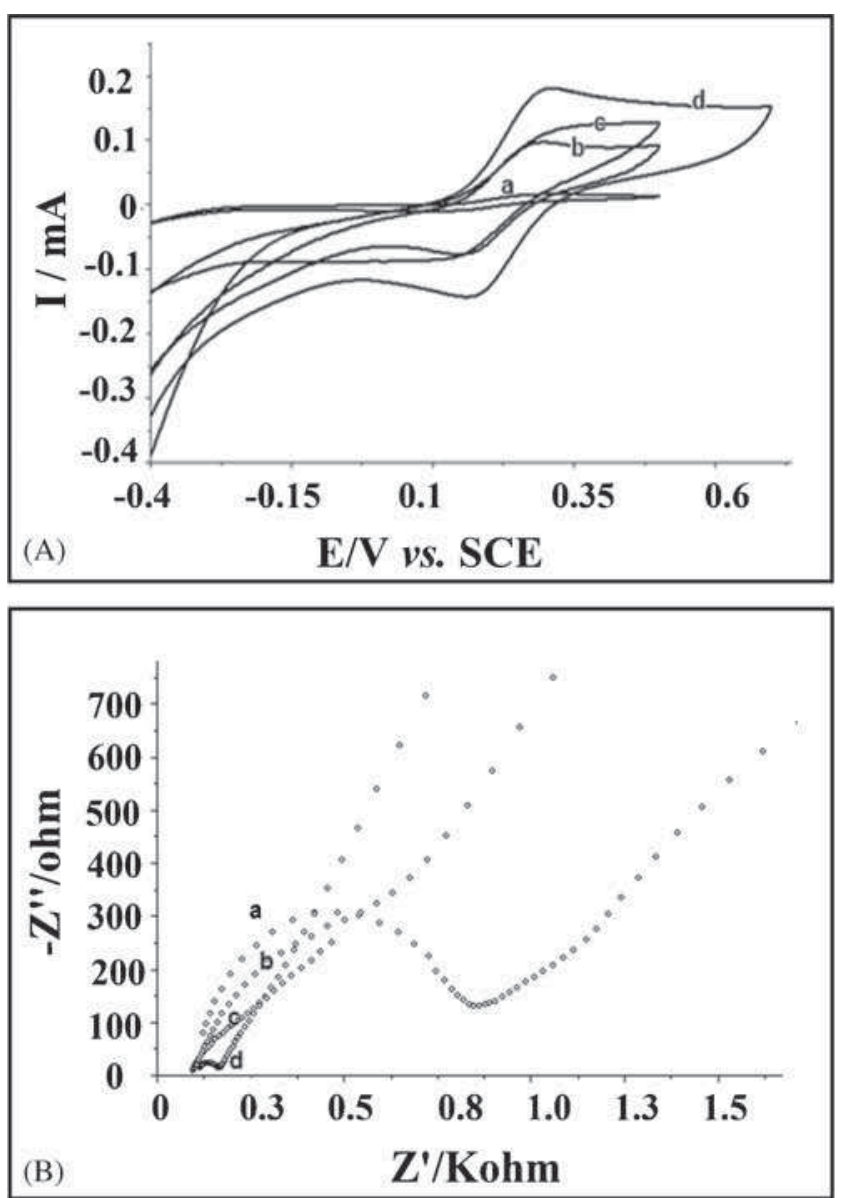

Figure 2. (A) Cyclic voltammograms and (B) Impedance spectra in solution of $1.0 \mathrm{mM}\left[\mathrm{Fe}(\mathrm{CN})_{6}\right]^{3-/ 4-}(1: 1), 0.1 \mathrm{M}$ $\mathrm{KCl}, \mathrm{pH} 7.00$, scan rate $100 \mathrm{mV} \mathrm{s}^{-1}$. Electrodes: CPE (a); $15 \%$ Au-MCPE (b), 15\% Pt-MCPE (c) and 15\% Au/Pt$\operatorname{MCPE}(\mathrm{d})$.

shows an arc with a given diameter of $810.78,768.59$, 500.64 and $71.58 \Omega$ for curves (a), (b), (c) and (d), respectively. It is clear that a lower charge transfer resistance is observed at bimetallic nanocomposite modified carbon paste electrode. This observation is in accordance with the results obtained from cyclic voltammetry. Therefore, other studies were focused on the $\mathrm{Au} / \mathrm{Pt}$ bimetallic nanocomposite modified CPE.

For choosing the optimized percentage of bimetallic nanocomposite, the carbon paste was modified by different percentages of $\mathrm{Au} / \mathrm{Pt}$ nanoparticles. The cyclic voltammetric measurements (figure $3 \mathrm{~A}$ ) depict the redox signal of $\left[\mathrm{Fe}(\mathrm{CN})_{6}\right]^{3-/ 4-}$ at the surface of CPE (curve a, Inset) increases significantly after modification by $1 \%$ of $\mathrm{Au} / \mathrm{Pt}$ nanoparticles (curve b). However after addition of 5\% (curve c) and 10\% (curve d), no obvious change takes place in the cyclic voltammogram. But, CPE modified with $15 \%$ of Au/Pt nanoparticles (curve e) shows the highest $\mathrm{CV}$ signal. After that, the modification of CPE was done by $20 \%$ and $30 \%$, curves $\mathrm{f}$ and $\mathrm{g}$, 

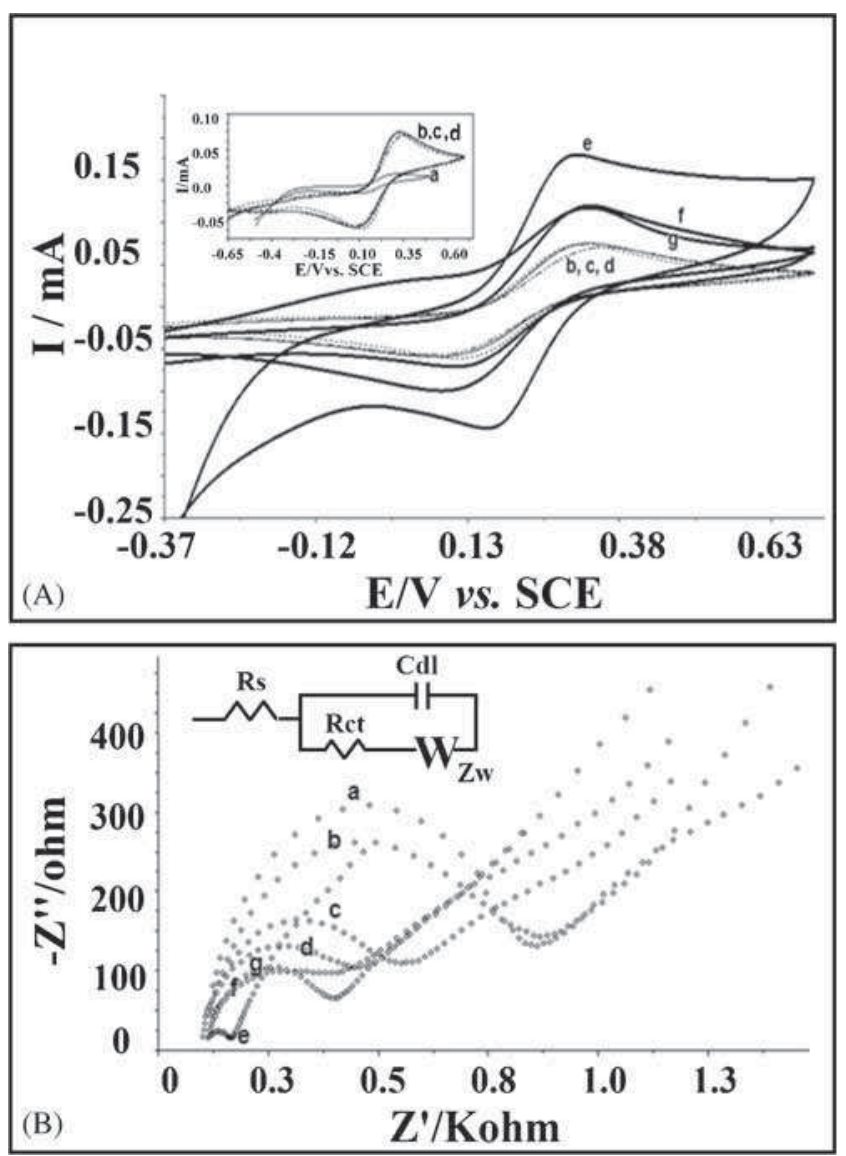

Figure 3. (A) Cyclic voltammograms and (B) Impedance spectra in solution of $1.0 \mathrm{mM}\left[\mathrm{Fe}(\mathrm{CN})_{6}\right]^{3-/ 4-}(1: 1), 0.1 \mathrm{M}$ $\mathrm{KCl}, \mathrm{pH} 7.00$, scan rate $100 \mathrm{mV} \mathrm{s}^{-1}$. Electrodes: CPE (a); Au/Pt-MCPE: $1 \%$ (b), $5 \%$ (c), $10 \%$ (d), $15 \%$ (e), $20 \%$ (f) and $30 \%(\mathrm{~g})$.

respectively. As seen, the CV currents decrease with increasing percent of nanocomposite. Our assumption is that higher amount of nanoparticles probably either decreases the smoothness of the surface of carbon paste electrode or increases the track and groove on the surface. It can cause the less conductivity of working electrode. Therefore, percentage composition of $15 \%$ was chosen as the optimized condition for nanocomposite modified carbon paste electrode.

Figure 3B shows the electrochemical impedance spectra at bare CPE and modified ones with different percentages of $\mathrm{Au} / \mathrm{Pt}$ nanoparticles. The diameter of semicircles is $810.78 \Omega$ (a), 797.56 (b), 504.80 (c), 427.74 (d), 71.58 (e), 453.76 (f) and (g) 324.49 for CPE, $1 \%, 5 \%, 10 \%, 15 \%, 20 \%$ and $30 \%$ Au/Pt-MCPE, respectively. As seen, the smallest semicircle belongs to $15 \% \mathrm{Au} / \mathrm{Pt}$-MCPE. Therefore, it can be concluded that this electrode has the best among the modified electrodes. As EIS illustrates the barrier properties of the electrode surfaces, ${ }^{32}$ this observation implies that nanoparticles probably aggregate in the percentage compositions higher than $15 \%$. Therefore, the unique properties of nanomaterials are ruined and the charge transfer resistance increases at the electrode surface.

\subsection{Immobilization of DNA}

To investigate the efficiency of the nanocomposite modified carbon paste electrodes, the differential pulse voltammetric response of G1-DNA $(1.0 \mu \mathrm{M})$ immobilized on the MCPE was monitored. The guanine oxidation signal at the CPE surface can be observed at around $1.05 \mathrm{~V}$ vs. SCE in the $20 \mathrm{mM}$ of Tris- $\mathrm{HCl}$ buffer solution (PH 7.00). ${ }^{36,37}$ As G1-DNA contains several guanines, they can be used as a reference to study which working electrode has better performance for genosensors. Differential pulse voltammogram and the histogram of guanine oxidation signal $\left(\mathrm{I}_{\mathrm{pa}}\right)$ of G1-DNA immobilized on the surface of different modified $\mathrm{CPE}$ are illustrated in figures $4 \mathrm{~A}$ and $4 \mathrm{~B}$, respectively. The oxidation peak currents are $0.110 \pm 0.036 \mu \mathrm{A}$ (a),
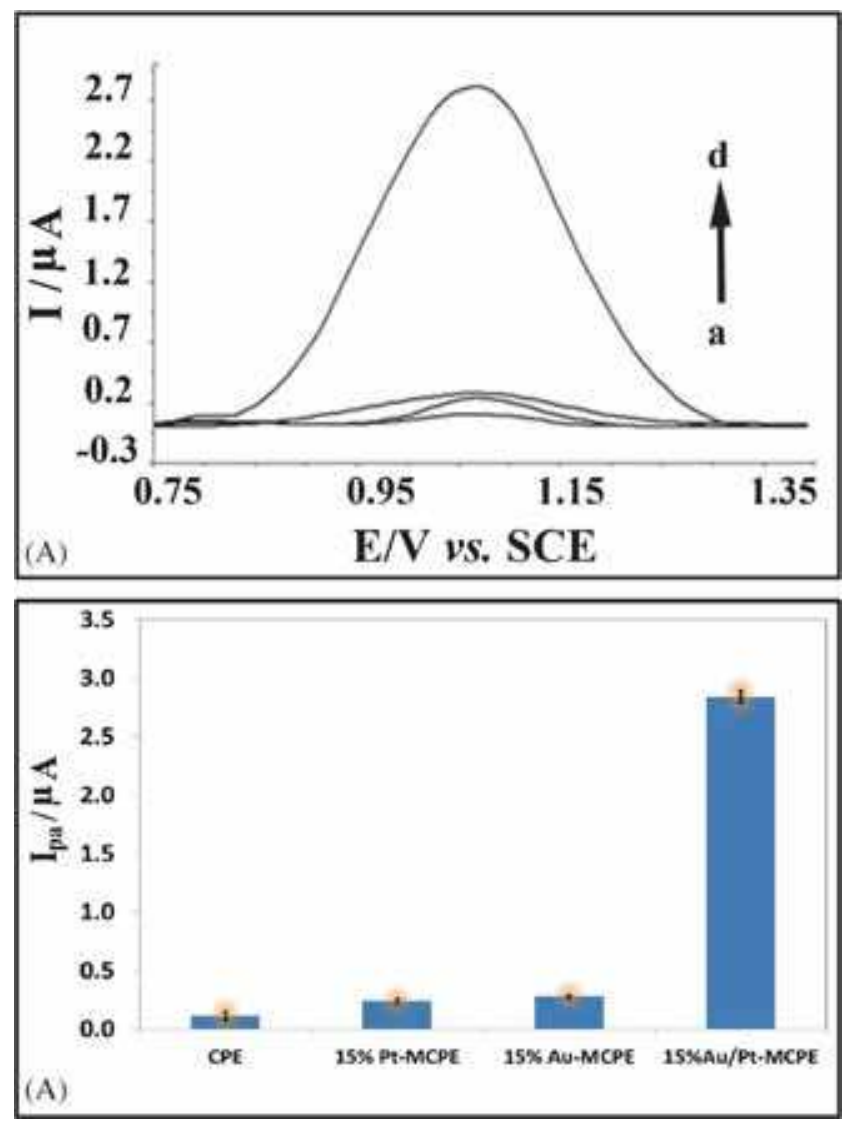

Figure 4. (A) Differential pulse voltammograms and (B) Histogram of DPV oxidation current signal of G1-DNA immobilized at the surface of CPE (a), 15\% Pt-MCPE (b), 15\% Au-MCPE (c), 15\% Au/Pt-MCPE (d). Experimental conditions: $20 \mathrm{mM}$ Tris- $\mathrm{HCl}$ buffer solution $(\mathrm{pH} 7.0)$ containing $20 \mathrm{mM} \mathrm{NaCl}$, pulse height: $0.05 \mathrm{~V}$, scan rate: $5 \mathrm{mV} \mathrm{s}^{-1}, 1.0 \mu \mathrm{M}$ oligonucleotide in accumulation solution. 
$0.239 \pm 0.020 \mu \mathrm{A}$ (b), $0.278 \pm 0.015 \mu \mathrm{A}$ (c), and $2.841 \pm 0.052 \mu \mathrm{A}(\mathrm{d})$ at the surface of $\mathrm{CPE}, 15 \%$ Pt-MCPE, 15\% Au-MCPE, and 15\% Au/Pt-MCPE, respectively. As seen, G1-DNA immobilized on the carbon paste electrode modified with $15 \%$ of $\mathrm{Au} / \mathrm{Pt}$ bimetallic nanoparticles has a high level of proficiency for DNA biosensor. Our supposition is that not only Pt nanoparticles could increase the electrode surface area, but also Au nanoparticles would enhance the amount of immobilized DNA due to biological compatibility of gold nanoparticles. ${ }^{38}$ So, Au/Pt bimetallic nanocomposite leads to a significantly improved performance in the proposed biosensor.

To find an optimum value for percentage composition of bimetallic nanocomposite modified electrode, MCPEs were prepared with various percent of $\mathrm{Au} / \mathrm{Pt}$ nanoparticles. Figures 5A and 5B illustrate DPVs and the histograms for guanine oxidation signal $\left(\mathrm{I}_{\mathrm{pa}}\right)$ of $\mathrm{G} 1$ DNA $(1.0 \mu \mathrm{M})$ immobilized on the surface of different MCPE, respectively. The oxidation peak currents are $0.113 \pm 0.035 \mu \mathrm{A}(\mathrm{a}), 0.546 \pm 0.050 \mu \mathrm{A}$ (b), $0.733 \pm$
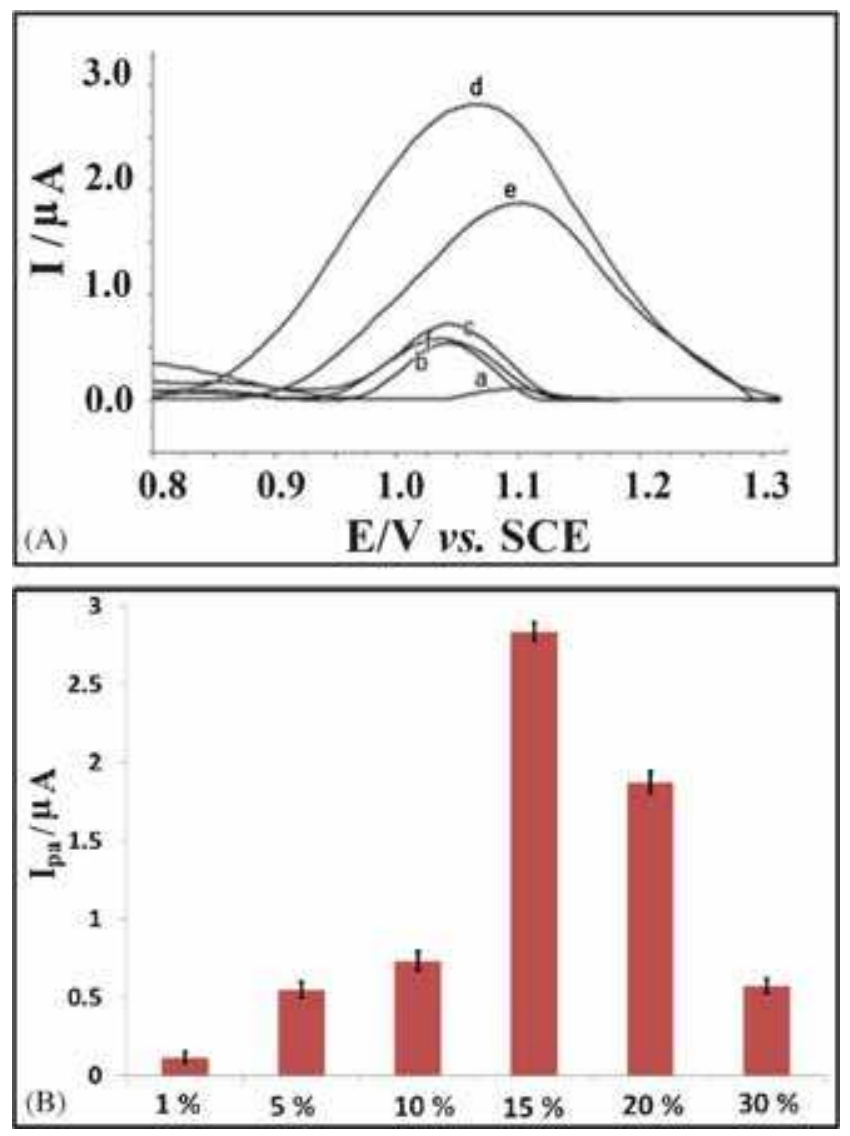

Figure 5. Differential pulse voltammograms and (B) Histogram of DPV oxidation current signal of G1-DNA immobilized at the surface of various percent of bimetallic Au/PtMCPE: $1 \%$ (a), 5\% (b), 10\% Au/Pt-MCPE (c), 15\% (d), 20\% (e), $30 \%$ (f). Experimental conditions: Same as in figure 4.
$0.061 \mu \mathrm{A}(\mathrm{c}), 2.841 \pm 0.052 \mu \mathrm{A}(\mathrm{d}), 1.873 \pm 0.072 \mu \mathrm{A}$ (e), and $0.573 \pm 0.045 \mu \mathrm{A}$ (f) at the surface of MCPEs containing $1 \%, 5 \%, 10 \%, 15 \%, 20 \%$, and $30 \% \mathrm{Au} / \mathrm{Pt}$ nanoparticles, respectively. As depicted in this figure, the activity of the electrode improves when the percent of $\mathrm{Au} / \mathrm{Pt}$ nanoparticles exceeded $1 \%$ until it reaches the maximum value at $15 \%$ and then decreases at higher percentages. As mentioned earlier, the higher percentage composition of nanoparticles/CPE can cause either decline the conductivity of the electrode or remove active sites of the working electrode surface. Also, there is a small shift in the position of guanine oxidation that can be explained by the proximity of the groups involved, due to the unfolding of the DNA helix. ${ }^{37}$

\subsection{Hybridization study}

To investigate the hybridization event, the differential pulse voltammetric response of C1-DNA as a probe immobilized on the 15\% Au/PT-MCPE before and after hybridization with G1-DNA as complementary sequence was monitored. Hybridization detection was carried out by monitoring the changes in the guanine oxidation current upon duplex formation as mentioned in literature. ${ }^{39-41}$

After the formation of DNA duplex chain, two opposed events take place in relation to the magnitude of the probe guanine oxidation signal. ${ }^{42}$ Firstly, the electrochemical signal of the probe free guanine bases is decreased upon hybridization with complementary cytosine bases on the target DNA. This is because of less availability of guanine bases in the hybrid for oxidation. Secondly, the electrochemical signal of guanine bases is increased due to increase in the number of total guanine bases in double-stranded DNA in comparison to single-stranded DNA. As these events are in competition with each other, this problem is solved by using a probe which contains preferably only one or a few guanine bases with several cytosines. The importance of the presence of only one guanine base relies on the possibility of probe immobilization monitoring and consequently, the possibility of probe immobilization optimizing on the electrode. Several cytosine bases in the probe are useful for hybridization with target DNA that contains several guanine bases. On the basis of this approach, the guanine oxidation signal remarkably increases after hybridization of probe with DNA target and therefore can be easily recorded. Short DNA sequences related to p53 gene (C1-DNA) used in this study was designed according to this strategy. As seen in figure 6 , the oxidation peak currents are $0.422 \pm$ $0.032 \mu \mathrm{A}$ (a) and $1.842 \pm 0.041 \mu \mathrm{A}$ for the probe before and after hybridization with complementary 


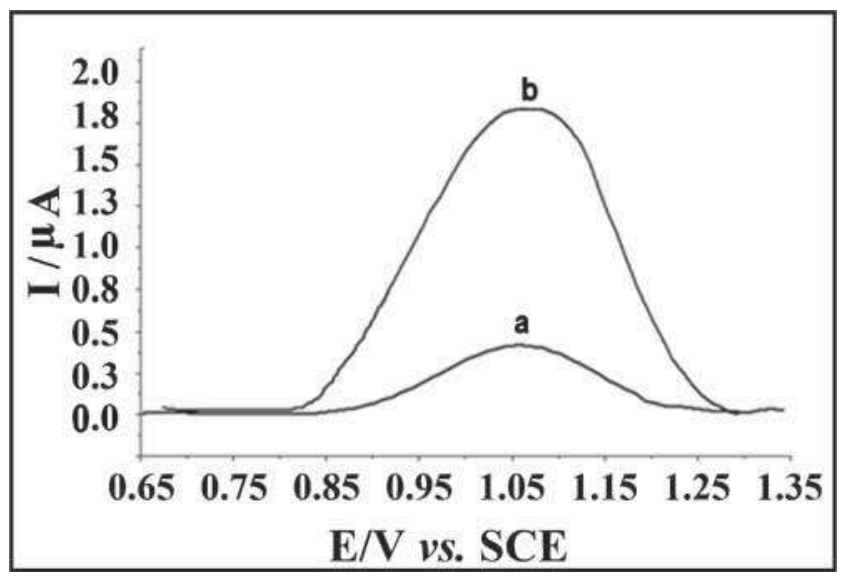

Figure 6. Differential pulse voltammograms of C1-DNA immobilized onto $15 \%$ Au/Pt-MCPE before hybridization (a) and after hybridization with G1-DNA as complementary (b). Experimental conditions: Same as in figure 4. C1- and G1-DNA concentration $1.0 \mu \mathrm{M}$.

DNA, respectively. The concentration of the probe and its complement is $1.0 \mu \mathrm{M}$. The nearly 4.37 -fold elevation after duplex formation is in agreement with the strategy.

\subsection{Investigation of plasmid samples}

Following the observation of good results in the electrochemical detection of DNA hybridization by differential pulse voltammetry for a synthetic short sequence of the p53 gene, plasmid samples of this gene were studied. Figure 7A shows DPV signals of C1-DNA $(1.0 \mu \mathrm{M})$ immobilized on the different working electrodes before hybridization ( $a, b, c$ and d) and after hybridization with plasmid samples containing complementary sequences $\left(a^{\prime}, b^{\prime}, c^{\prime}\right.$ and $\left.d^{\prime}\right)$. In this figure, curves $a, b, c$ and $d$ pertain to CPE, 15\% Pt-MCPE, 15\% Au-MCPE and 15\% $\mathrm{Au} / \mathrm{Pt}-\mathrm{MCPE}$, respectively. As seen, there is a shift in the peak potential for guanine oxidation with respect to electrode materials ( $\Delta \mathrm{V} \cong 0.3 \mathrm{~V}$ from b to $\mathrm{d}$ ). It clearly confirms that the oxidation of guanine is easier at the surface of Au/Pt-MCPE; because it is oxidized at lower positive potential.

Figure 7B depicts histograms for the guanine oxidation signals of DNA samples before and after hybridization with complementary plasmid $\left(7.40 \mathrm{ng} \mu \mathrm{L}^{-1}\right)$. As seen, the difference between guanine oxidation signals before and after hybridization with complementary DNA plasmid $(\Delta \mathrm{I})$ are nearly $0.017 \pm 0.035 \mu \mathrm{A}, 1.070$ $\pm 0.021 \mu \mathrm{A}, 1.201 \pm 0.032 \mu \mathrm{A}$ and $1.500 \pm 0.018 \mu \mathrm{A}$ for CPE, 15\% Pt-MCPE, 15\% Au-MCPE and 15\% $\mathrm{Au} / \mathrm{Pt}-\mathrm{MCPE}$, respectively. It can be concluded that the bimetallic nanocomposite-modified CPE has the best ability to detect hybridization between the probe and its complementary plasmid.
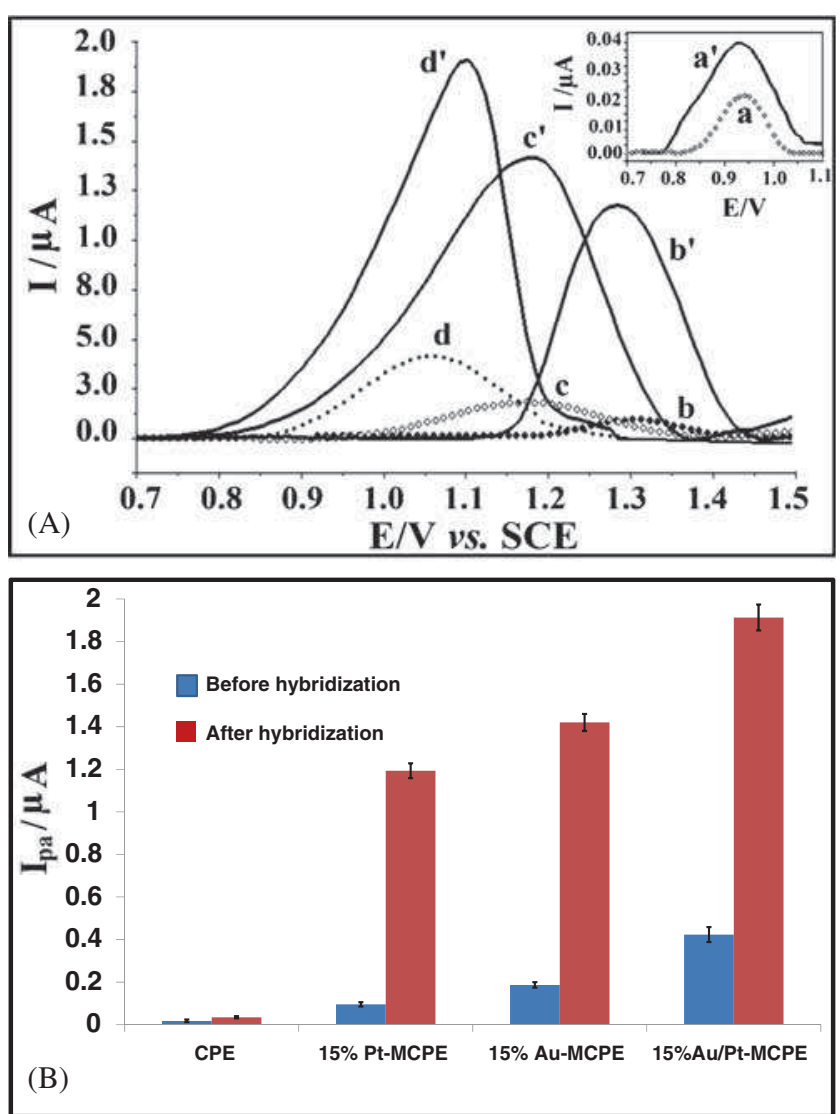

Figure 7. (A) Differential pulse voltammograms and (B) Histogram of DPV oxidation current signal of C1-DNA immobilized at the surface of CPE (a), 15\% Pt-MCPE (b), 15\% Au-MCPE (c), 15\% Au/Pt-MCPE (d)before hybridization and after hybridization with complementary DNA plas$\operatorname{mid}\left(\mathrm{a}^{\prime}, \mathrm{b}^{\prime}, \mathrm{c}^{\prime}, \mathrm{d}^{\prime}\right)$. Experimental conditions: Same as in figure 4. DNA probe concentration $1.0 \mu \mathrm{M}$, complementary DNA plasmid (7.40 ng $\left.\mu \mathrm{L}^{-1}\right)$.

\subsection{Selectivity Study}

The selectivity of the proposed DNA sensor to the target was studied via performance of some hybridization experiments with non-complementary oligonucleotides. For this purpose, two different plasmid samples, Pet and TL, with non-complementary oligonucleotides sequences were used in the control experiment. Figure 8 shows DPV of C1-DNA immobilized on the surface of $15 \% \mathrm{Au} / \mathrm{Pt}-\mathrm{MCPE}$ before hybridization (a) and after hybridization with non-complementary plasmid Pet (b), TL (c), and after hybridization with complementary plasmid (f). Plasmid concentrations are $37 \mathrm{ng} \mu \mathrm{g}^{-1}$ in all the samples. As shown, the interaction between these non-complementary plasmids and C1-DNA $(1 \mu \mathrm{M})$ as the probe did not lead to a significant increase in the guanine oxidation signal $(8.0 \%$ and $10.5 \%$ increase for Pet and TL, respectively) because hybridization of the probe with the DNAs did not occur entirely. Slightly 


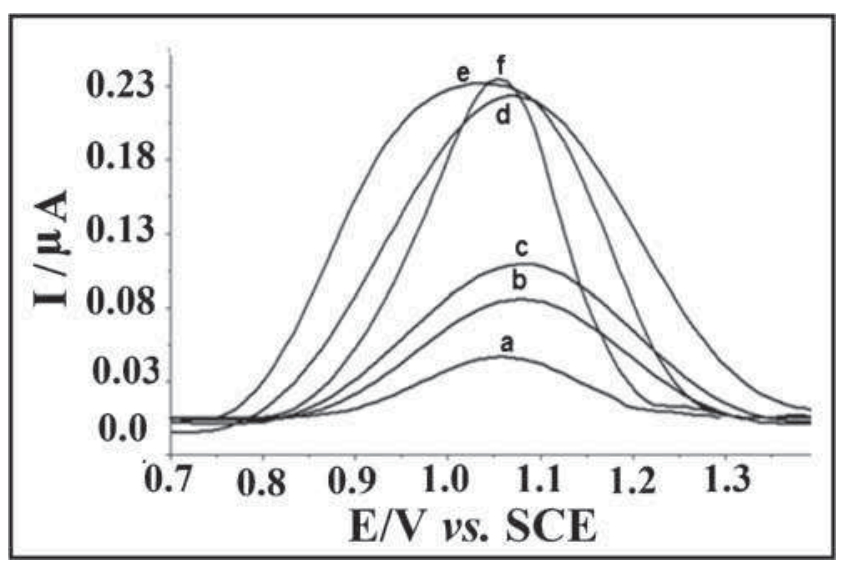

Figure 8. Differential pulse voltammograms of C1-DNA immobilized at the surface of $15 \% \mathrm{Au} / \mathrm{Pt}-\mathrm{MCPE}$ before hybridization (a) and after hybridization with non-complementary plasmid Pet (b), TL (c), mixture of Pet and complementary plasmid (d), mixture of TL and complementary plasmid (e), and after hybridization with complementary plasmid (f). Experimental conditions: Same as in figure 4. Concentration of DNA probe: $1.0 \mu \mathrm{M}$, DNA plasmid: $37.0 \mathrm{ng} \mu \mathrm{L}^{-1}$.

increased guanine signal may be attributed to the negligible adsorption of the non-complementary oligonucleotides on some free sites present at the surface of working electrode or short and non-complete hybridization between the probe and non-complementary DNAs, because DNA probe is immobilized at the surface of activated working electrode via applied potential. Therefore, somehow DNA probe is horizontally placed at the surface. It means that it cannot recognize the target perfectly in comparison with DNA probe vertically placed at the surface of the working electrode via formation of self-assembled monolayers. ${ }^{43}$

The DNA sensor selectivity was also investigated in plasmid samples containing both complementary and non-complementary sequences. The curves $d$ and $\mathrm{e}$ in figure 8 display the DPV of the probe immobilized on the electrode after hybridization in binary mixtures of Pet/complementary plasmid (20\% increase in signal) and TL/complementary plasmid (21\% increase in signal), respectively. As illustrated, the interactions between G1-DNA and Pet or TL in the mixture solution have less effect on the hybridization event between probe and target plasmid (23\% increase in signal). However, the guanine signal decreases slightly, probably because of partial hybridization occurred between the probe and non-complementary plasmid and also between target and non-complementary oligonucleotides in the mixture solution. These interactions give rise to a slight decrease in availability and hybridization between G1-DNA plasmid and immobilized probe.

\subsection{Investigation of detection limit}

The diagnostic performance of the sensor was studied by hybridization investigation between C1-DNA probe $(1.0 \mu \mathrm{M})$ and different concentrations of complementary plasmid sample. Figure 9A shows the DPV signals of guanine oxidation after hybridization with increasing

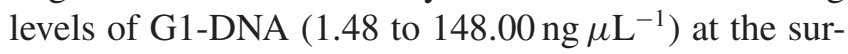
face of $15 \% \mathrm{Au} / \mathrm{Pt}$-MCPE. The variation of the voltammetric response versus G1-DNA plasmid concentration is shown in figure 9B. As seen, $\mathrm{Ip}_{\mathrm{a}}$ increases with increasing of plasmid concentration and levels off at ca. $148.00 \mathrm{ng} \mu \mathrm{L}^{-1}$ and there is a good logarithmic dependency in the obtained results. The inset of this figure clarifies the linear dependence between $\mathrm{I}_{\mathrm{pa}}$ and Logarithm of concentration of DNA in this range. The detection limit was estimated about $0.0531 \mathrm{ng} \mu \mathrm{L}^{-1}$.
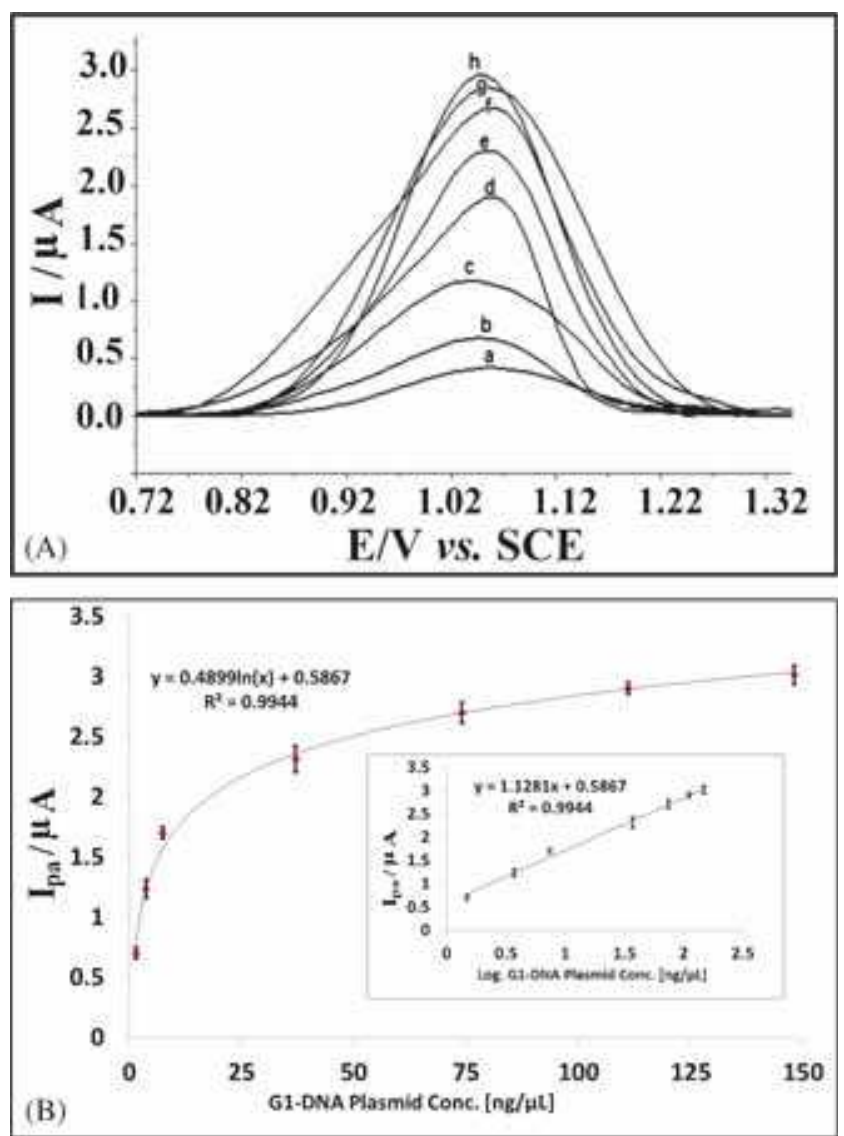

Figure 9. (A) Differential pulse voltammograms of C1DN immobilized $(1.0 \mu \mathrm{M})$ at the surface of $15 \% \mathrm{Au} / \mathrm{Pt}-\mathrm{MCPE}$ before hybridization (a) and after hybridization with different concentrations of complementary plasmid: $1.48 \mathrm{ng} \mu \mathrm{L}^{-1}$ (b), $3.70 \mathrm{ng} \mu \mathrm{L}^{-1}$ (c) $7.40 \mathrm{ng} \mu \mathrm{L}^{-1}$ (d) $37.00 \mathrm{ng} \mu \mathrm{L}^{-1}$ (e)

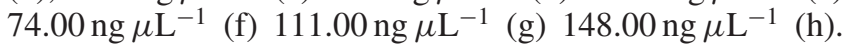
(B) Variation of guanine oxidation signal of the probe immobilized electrode in the absence and presence of complementary plasmid. Inset: Calibration plot of $\mathrm{I}_{\mathrm{pa}}$ versus Logarithm of concentration of G1-DNA plasmid. 
As the sensitivity corresponds to the slope of the calibration curve, the sensitivity is about $1.12 \mu \mathrm{A} / \mathrm{ng} \mu \mathrm{L}^{-1}$ with $\mathrm{R}^{2}=0.99$ that shows a good response of this biosensor. If we consider the stability as the length of time that these modified CPEs can be stored, it can be said that they are completely stable for six months in room temperature. For reproducibility, every time that the working electrode is polished with the paper, there is a refreshed working electrode that is totally same as previous one, as far as the paste is completely mixed and uniform.

\section{Conclusion}

Recent development in nanotechnology has paved the way for a large number of alloyed nanomaterials and devices with desirable properties for electrochemical sensor and biosensor applications. Noble metal nanoparticles such as gold and platinum have been used particularly for signal amplification in numerous biodiagnostic devices. In this work, bimetallic nanocomposite-modified carbon paste electrode was prepared by mixing of carbon paste with different percentage of $\mathrm{Au}$ and Pt nanoparticles. This study illustrated that the use of Au/Pt-MCPE improved the electrochemical signals and sensitivity of the biosensing procedure and $15 \%$ $\mathrm{Au} / \mathrm{Pt}$-MCPE was found to be the best working electrode. The short sequence of the p53 gene was selected as a probe for detection of DNA plasmid. The enhancement of guanine oxidation current after duplex formation between probe and DNA target was used to monitor the hybridization event. The results of selectivity study revealed that only complementary G1-DNA as the target plasmid can form an effective duplex with C1-DNA as the probe and consequently cause a significant increase in the guanine oxidation signal. The LOD showed good diagnostic performance of this label-free genosensor. Finally, the desirable electrochemical activity of $\mathrm{Au} / \mathrm{Pt}$ bimetallic nanocomposite can be attributed to the distinguishing properties of platinum and gold nanoparticles.

\section{References}

1. Silva M M S, Cavalcanti I T, Barroso M F, Sales M G and Dutra R F 2010 J. Chem. Sci. 122911

2. Hamidi-Asl E, Palchetti I, Hasheminejad E and Mascini M 2013 Talanta 11574

3. Ilkhani H, Arvand M, Ganjali M R, Marrazza G and Mascini M 2013 Electroanalysis 25507

4. Gilmartina N and O'Kennedy R 2012 Enzy. Micr. Tech. 5087

5. Ilkhani H, Ganjali M R, Arvand M, Hejazi M S, Azimi F and Norouzi P 2011 Int. J. Biol. Macromol. 491117
6. Bettazzi F, Hamid-Asl E, Esposito C L, Quintavalle C, Formisano N, Laschi S, Catuogno S, Iaboni M, Marrazza G, Mascini M, Cerchia L, De Franciscis V, Condorelli G and Palchetti I 2013 Anal. Bioanal. Chem. 4051025

7. Daems D, Van Nuijs A L N, Covaci A, Hamidi-Asl E, Van Camp G and Nagels L J 2015 Biomed. Chromatogr. 29(7) 1124

8. Hamidi-Asl E, Daems D, De Wael K, Van Camp G and Nagels L J 2014 Anal. Chem. 8612243

9. Hejazi M S, Majidi M R, Gholizadeh S, Hamidi-Asl E, Turner A P F and Golabi S M 2015 J. Nanosci. Nanotechnol. 153405

10. Alipour E, Pournaghi-Azar M H, Parvizi M, Golabi S M and Hejazi M S 2011 Electrochim. Acta 561925

11. Hamidi-Asl E, Dardenne F, Blust R and De Wael K 2015 Sensors 157605

12. Pérez-López B and Merkoçi A 2011 Anal Bioanal. Chem. 3991577

13. Hejazi M S, Hamidi-Asl E, Majidi M R, Gholizadeh S, Turner A P F and Golabi S M 2015 J. Nanosci. Nanotechnol. 15(5) 3405

14. Chen K J, Lee C F, Rick J, Wang S H, Liu C C and Hwang B J 2012 Biosens. Bioelectron. 3375

15. Lee K S, Son J M, Jeong D Y, Lee T S and Kim W M 2010 Sensors 1011390

16. Gholivand M B, Azadbakht A and Pashabadi A 2011 Electroanalysis 232771

17. Huang S J and Chen P Y 2013 Electrochim. Acta 89180

18. Cao X, Wang N, Jia S, Guo L and Li K 2013 Biosens. Bioelectron. 39226

19. Li X, Li B, Cheng M, Du Y, Wang X and Yang P 2008 J. Mol. Cat. A: Chem. 2841

20. Hamidi-Asl E, Raoof J B, Ojani R and Hejazi M S 2013 Electroanalysis 252075

21. Bagheryan Z, Raoof J B, Ojani R and Hamidi-Asl E 2013 Electroanalysis 252659

22. Raoof J B, Ojani R, Ebrahimi M and Hamidi-Asl E 2011 Chin. J. Chem. 292541

23. Hejazi M S, Raoof J B, Ojani R, Golabi S M and Hamidi-Asl E 2010 Bioelectrochem 78141

24. Asghary M, Raoof J B, Hamidi-Asl E and Ojani R 2015 J. Nanosci. Nanotechnol. 153394

25. Hamidi-Asl E, Raoof J B, Samadi Meibodi A and Haghnavaz Bazgir Z 2015 Sci. China Chem. 58(1) 1

26. Raoof J B, Ojani R, Golabi S M, Hamidi-Asl E and Hejazi M S 2011 Sens. Actuators B 157195

27. Azizi S N, Ranjbar S, Raoof J B and Hamidi-Asl E 2013 Sens. Actuators B 181319

28. Hamidi-Asl E, Raoof J B, Ojani R, Golabi S M and Hejazi M S 2013 J. Iran. Chem. Soc. 101075

29. Hamidi-Asl E, Raoof J B, Hejazi M S, Sharifi S, Golabi S M, Palchetti I and Mascini M 2015 Electroanalysis 27 1378

30. Baghery Hashkavayi A, Raoof J B, Ojani R and HamidiAsl E 2015 Electroanalysis 271449

31. Mousavi-Sani S Z, Raoof J B, Ojani R and Hamidi-Asl E 2013 J. Chin. Chem. Soc. 60650

32. Raoof J B, Hejazi M S, Ojani R and Hamidi-Asl E 2009 Int. J. Electrochem. Sci. 41436

33. Hejazi M S, Pournaghi-Azar M H, Alipour E and Karimi F 2008 Biosens. Bioelectron. 231588 
34. Xiao X and Bard A J 2007 J. Am. Chem. Soc. 129 9610

35. Saha K, Agasti S S, Kim C, Li X and Rotello V M 2012 Chem. Rev. 1122739

36. Xie H, Yang D, Heller A and Gao Z 2007 Biophys. J. 92(8) L 70

37. Brett A M O and Serrano S H P 1995 J. Braz. Chem. Soc. 697

38. Wang M, Sun C, Wang L, Ji X, Bai Y, Li T and Li J 2003 J. Pharm. Biomed. 331117
39. Pournaghi-Azar M H, Hejazi M S and Alipour E 2007 Electroanalysis 19466

40. Pournaghi-Azar M H, Alipour E, Zununi S, Froohandeh $\mathrm{H}$ and Hejazi M S 2008 Biosens. Bioelectron. 24524

41. Hejazi M S, Alipour E and Pournaghi-Azar M H 2007 Talanta 711734

42. Pournaghi-Azar M H, Hejazi M S and Alipour E 2006 Anal. Chim. Acta $\mathbf{5 7 0} 144$

43. Higuchi M, Koga T, Taguchi K and Kinoshita T 2002 Chem. Commun. 1126 